\title{
MATERNAL MORBIDITY: ANALYSIS WITH MAJOR DEGREE OF PLACENTA-PREVIA IN WOMEN WITH PREVIOUSLY SCARRED UTERUS drpinky@hotmail.com
}

1, FCPS II trainee,

Laiquat Hospital, Jamshoro

2, FCPS II trainee,

Laiquat Hospital, Jamshoro

Correspondence Address:

Dr. Sumera Shaikh

FCPS II trainee,

Laiquat Hospital, Jamshoro

drpinky@hotmail.com

Article received on: 26/01/2016

Accepted for publication: 02/09/2016

Received after proof reading: 07/10/2016

\section{Dr. Sumera Shaikh1, Dr. Kiran Wassan²}

\begin{abstract}
Objective ... To determine the frequency of maternal morbidity in patients with major degree of placenta previa in a previously scarred uterus. Study Design: Descriptive study. Setting: Department of Obstetrics and Gynecology Liquat University of medical and Health Sciences, Jamshoro. Period: April $1^{\text {st }} 2012$ to Sep $30^{\text {th }}$ 2012. Methods: The data was collected on pre-designed pro-forma by the researcher. Tools and techniques were analyzed through SPSS version 15. Results The Following results were drawn by the study: The mean age of enrolled participants was $32.5 \pm 4.7$ years, mean parity was $3.8 \pm 1.4$ and mean gestational age was $34.7 \pm 2.9$ weeks. The frequency of morbidly adherent placenta was $23.7 \%$, postpartum hemorrhage $21.9 \%$, blood transfusion $>447.2 \%$ and cesarean hystrectomy was $12.3 \%$ cases. Conclusions: It is concluded from this study that morbidly adherent placenta was $23.7 \%$, postpartum hemorrhage $21.9 \%$, blood transfusion $>447.2 \%$ and cesarean hystrectomy was $12.3 \%$ cases.
\end{abstract}

Key words: $\quad$ Scarred uterus, postpartum hemorrhage, blood transfusions, cesarean hysterectomy.

Article Citation: Shaikh S, Wassan K. Maternal morbidity: Analysis with major degree of placenta-previa in women with previously scarred uterus. Professional Med J 2016;23(10):1183-1186. DOI: 10.17957/TPMJ/16.3263

\section{INTRODUCTION}

Placenta previa refers to a placenta that is situated wholly or partly in the lower uterine segment. It is associated with significant maternal and fetal morbidity and mortality because of blood loss and is one of the acute life threatening emergencies in the obstetrics. ${ }^{1}$

Rouse et al., revealed in a recent study of association between cesarean section and blood transfusion that repeat cesarean deliveries are linked with increased risk of blood transfusion in patient with placenta previa. ${ }^{2}$

The major risk of morbidly adhered placenta is uterine scar. The three degrees of adherence have been described accrete, increta, percreta, where the placenta adhere to or invade into or through the uterine wall because of abnormal development of decidua basilis. ${ }^{3}$

The incidence of placenta previa is variable depending on the population and background cesarean rate, with rates from $0.4-0.8 \%$ reported. ${ }^{4}$ Antepartum hemorrhage is major obstetrical problem. Although many studies are carried out worldwide including Pakistan, this study is conducting in our set up (Pakistan). My concern regarding this study is to reduce the morbidity associated with the major degree of placenta previa by early detection of the problem and to anticipate the problem associated with cesarean section and giving awareness to the women in whom their c/section is performed on their wish.

\section{SUBJECTS AND METHODS}

This Descriptive Case study research was conducted in Department of Obstetrics and gynecology Liaquat University Hospital Hyderabad from April $1^{\text {st }} 2012$ to Sep $30^{\text {th }}$ 2012. In patient (114) women of reproductive age group with gestational age more than 28 weeks were analyzed through Non probability purposive sampling method. The information was collected through pre designed pro-forma containing close ended questions. The data 
was analysed through SPSS version 15.

Women, admitted in gynae unit II, fulfilling the inclusion criteria were recruited for the study (Inclusion criteria : Patients of any age with history of cesaren section having ultrasound diagnosis of placenta previa type III and IV ( showing that placenta covering the cervical so partially i-e type III or completely i-e type IV placenta previa. While for exclusion criteria: Gestational age < 28 week, abruptio placenta, patient with scar other than cesarean section).

Informed consent was taken. Gestational age at diagnosis and delivery was noted. The diagnosis of morbidly adherent placenta and cesarean hysterectomy was made as per operational definition.

Requirement of blood transfusion of $>4$ units was noted during surgery and in post-op erative period. Estimated blood loss was noted during surgery, within 24 hours after surgery and during her stay in hospital. Patient was observed in the post-operative period for the follow up daily till discharge.

\section{RESULTS}

A total of 114 patients were studied in this research during study phase. The mean age of studied participants was $32.5 \pm 4.7$ years (Graph 1), mean parity was $3.8 \pm 1.4$ (Graph 2) and mean gestational age was $34.7 \pm 2.9$ weeks (Graph 3 ).

The frequency of morbidly adherent placenta was $23.7 \%$, postpartum hemorrhage $21.9 \%$, blood transfusion $>47.2 \%$ and cesarean hystrectomy was $12.3 \%$ cases (Graph 4 ).

\begin{tabular}{|l|c|c|c|}
\hline $\begin{array}{l}\text { Morbidly } \\
\text { adherent } \\
\text { placenta }\end{array}$ & $\mathbf{3 0}$ years & $>\mathbf{3 0}$ years & Total \\
\hline Yes & $12(27.3 \%)$ & $15(21.4 \%)$ & 27 \\
\hline No & $32(72.7 \%)$ & $55(78.6 \%)$ & 87 \\
\hline Total & 44 & 70 & 114 \\
\hline Table-I. Stratification of morbidly adherent placenta \\
by age \\
\hline \multicolumn{4}{|c|}{\begin{tabular}{c} 
P-value: 0.47 \\
\hline
\end{tabular}} \\
\hline
\end{tabular}

\begin{tabular}{|l|c|c|c|}
\hline \multirow{2}{*}{$\begin{array}{c}\text { Morbidly } \\
\text { adherent } \\
\text { placenta }\end{array}$} & \multicolumn{2}{|c|}{ Parity } & Total \\
\hline Yes & $22(27.8 \%)$ & $5(14.3 \%)$ & 27 \\
\hline No & $57(72.2 \%)$ & $30(85.7 \%)$ & 87 \\
\hline Total & 79 & 35 & 114 \\
\hline
\end{tabular}

Table-II. Stratification of morbidly adherent placenta by parity

P-value: 0.0

\begin{tabular}{|c|c|c|c|}
\hline \multirow{2}{*}{ PPH } & \multicolumn{2}{|c|}{ Age } & Total \\
\hline Yes & $\mathbf{3 0}$ years & $\mathbf{> 3 0}$ years & \\
\hline No & $32(27.3 \%)$ & $13(18.6 \%)$ & 25 \\
\hline Total & 44 & $57(81.4 \%)$ & 89 \\
\hline
\end{tabular}

Table-III. Stratification of postpartum hemorrhage by age

P-value: 0.274

\begin{tabular}{|c|c|c|c|}
\hline \multirow{2}{*}{ PPH } & \multicolumn{2}{|c|}{ Parity } & \multirow{2}{*}{ Total } \\
\hline Yes & Para 2 & Para $>\mathbf{2}$ & \\
\hline No & $62(78.5 \%)$ & $8(22.9 \%)$ & 25 \\
\hline Total & 79 & $27(77.1 \%)$ & 89 \\
\hline
\end{tabular}

Table-IV. Stratification of postpartum hemorrhage by parity

P-value: 0.873

\begin{tabular}{|c|c|c|c|}
\hline $\begin{array}{c}\text { Blood } \\
\text { transfusion } \\
\mathbf{> 4}\end{array}$ & $\mathbf{3 0}$ years & $\mathbf{3}$ 30 years & \multicolumn{1}{|c|}{ Total } \\
\hline Yes & $21(47.7 \%)$ & $33(\mathbf{4 7 . 1} \%)$ & 54 \\
\hline No & $23(52.3 \%)$ & $37(52.9 \%)$ & 60 \\
\hline Total & 44 & 70 & 114 \\
\hline
\end{tabular}

Table-V. Stratification of blood transfusion $>4$ by age P-value: 0.951

\begin{tabular}{|c|c|c|c|}
\hline $\begin{array}{c}\text { Blood } \\
\text { transfusion } \\
\mathbf{>}\end{array}$ & \multicolumn{2}{|c|}{ Parity } & Total \\
\hline Yes & Para 2 & Para $>\mathbf{2}$ & \\
\hline No & $41(48.1 \%)$ & $16(45.7 \%)$ & 54 \\
\hline Total & 79 & 35 & 114 \\
\hline
\end{tabular}

Table-VI. Stratification of blood transfusion $>4$ by parity

P-value: 0.813 


\begin{tabular}{|l|l|l|l|}
\hline \multirow{2}{*}{$\begin{array}{c}\text { Cesarean } \\
\text { hysterectomy }\end{array}$} & \multicolumn{2}{|c|}{ Age } & \multirow{2}{*}{ Total } \\
\hline Yes & 7 years & $\mathbf{7 3 0}$ years & \\
\hline No & $37(15.9 \%)$ & $7(10 \%)$ & 14 \\
\hline Total & 44 & 70 & 100 \\
\hline
\end{tabular}

Table-VII. Stratification of cesarean hystrectomy by age

P-value: 0.349

\begin{tabular}{|c|c|c|c|}
\hline $\begin{array}{c}\text { Cesarean } \\
\text { hystrectomy }\end{array}$ & Para 2 & Para >2 & Total \\
\hline Yes & $11(13.9 \%)$ & $3(8.6 \%)$ & 14 \\
\hline No & $68(86.1 \%)$ & $32(91.4 \%)$ & 100 \\
\hline Total & 79 & 35 & 114 \\
\hline Table-VIII. Stratification of cesarean hystrectomy by \\
parity \\
P-value: 0.32 \\
\hline
\end{tabular}

\section{DISCUSSION}

A major cause of morbidity and mortality in both developed and underdeveloped countries like Pakistan is placenta praevia. ${ }^{1}$ The aim of the study was to look for frequency of maternal morbidity of placenta praevia with scarred uterus.

Scarred uterus is highly attributable to cesarean sections. Day by day increasing numbers of cesarean section are alarming sign due to increasing health care cost and it is directly connected with maternal morbidity and mortality. ${ }^{5}$ The increase in maternal morbidity caused by repeated cesarean delivery is not limited to immediate operative complications but extends throughout a women's reproductive life. ${ }^{6}$ In this study we found that the frequency of morbidly adherent placenta was $23.7 \%$, postpartum hemorrhage $21.9 \%$, blood transfusion $>447.2 \%$ and cesarean hystrectomy was $12.3 \%$ cases. In a study regarding maternal morbidity, 13 (23.63 \%) patients developed PPH. Morbidly adherent placenta previa was found in $46 \%$ cases. Placenta previa is isometry cause of post-partum hemorrhage (PPH). Similarly, due to this emergency obstetrical hysterectomy rate is increasing, $53.84 \%$ patients experienced cesarean hysterectomy. ${ }^{7}$

\section{A study conducted by Shabnam Naz et al}

showed the incidence of morbidities associated with placenta previa in scarred uterus at Larkana, she noticed $20 \%$ incidence of postpartum hemorrhage, $8 \% \mathrm{c} /$ section end up in cesarean hysterectomies and $92 \%$ need blood transfusion. The placenta previa is associated with high parity, increased maternal age, uterine abnormalities smoking and previous cesarean section. ${ }^{4}$

In a study by Kiondo et al reported the predictors for severe bleeding in parturients with placenta praevia were: previous history of evacuation of the uterus or dilation and curettage (O.R. 3.6, Cl: 1.1$12.5)$, delivery by caesarean section in previous pregnancy (O.R. 19.9, Cl: 6.4-61.7). Here we can observe that there is high association of previous cesarean section and bleeding due to placenta and the confidence interval showed that it was statistically significant. ${ }^{8}$

In a study it was assumed that, by 2020 the cesarean section rate will be near to $56.2 \%$ with the rate of placenta previas 6,236 , rate of placenta accretas 4,504 with annually 130 maternal death rates. If present primary and secondary cesarean rates continue roughly, within 06 years these complications may rise. $^{9}$

The major causes of increasing cesarean section rates in our society are illiteracy, early/delay marriages, flaws in healthcare system along with professional incompetency, poverty, poor referral systems and incapable departmental policies toward the issue.

Different clinical methods may help to reduce caesarian section; 1. Regarding clinical assessment and sound judgement before carrying out primary cesarean section, 2. Experimental normal delivery (vaginal) after previous cesarean section, 3 . Limits the family to 3 by age of 30,4 . Use of contraceptive methods after 30 . Furthermore, these methods may help to reduce occurrences of placenta previa at reasonably low rate.

\section{CONCLUSION}

It was concluded from the study the frequency of Morbidly adherent placenta was $23.7 \%$, 
having Postpartum hemorrhage 21.9\%, Blood transfusion $>447.2 \%$ and Cesarean hystrectomy was $12.3 \%$ in such cases.

Copyright@ 02 Sep,2016.

\section{REFERENCES}

1. Hendricks MS, Chow YH, Bhagavath B, Singh K. Previous Cesarean section and abortion as risk factor for developing placenta previa. Obstet Gynaecol Res. 1999 Apr; 25(2):137-42.

2. William AG, Rabecca G, Mark B, Catheterine YS, Kenneth JL, Dewight JR, et al. Pregnancy outcome for women with placenta previa in relation to number of previous cesarean deliveries. Obstet Gynacol. 2007 Dec; 110(6):1249-55.

3. Naz S, Parveen R, Bhatti. A Majore placenta previa a true obstetric emergency. Med Channel. 2009 Sep; 15(3):74-7.

4. Silver R, Depp R, Sabbagha RE. Placenta previa: aggressive expectant management. Am J Obstet
Gynecol. 1984 Sep; 150 (1):15-22.

5. Rahim R, Shafqat T, Fayas $S$. An analysis of association of sacrred uterus with placenta previa and morbid adherence of placenta. J Med Sci. 2009 Jul; 17(2):603.

6. McShane PM, Heyl PS, Epstein MF. Maternal and perinatal morbidity resulting from placenta previa. Obstet Gynecol. 1985 Feb; 65 (2):176-82.

7. Varma TR. Fetal growth and placental function in patients with placenta praevia. J Obstet Gynaecol $\mathrm{Br}$ Commonw. 1973 Apr; 80 (4):311-5.

8. Kiondo P, Wandabwa J, Doyle P. Risk factors for placenta praevia presenting with severe vaginal bleeding in Mulago hospital, Kampala, Uganda. Afr Health Sci. 2008 Mar; 8(1):44-9.

9. Solheim KN, Esakoff TF, Little SE, Cheng YW, Sparks $T N$, Caughey AB. The effect of cesarean delivery rates on the future incidence of placenta previa, placenta accreta, and maternal mortality. J Matern Fetal Neonatal Med. 2011 Nov; 24(11):1341-6.

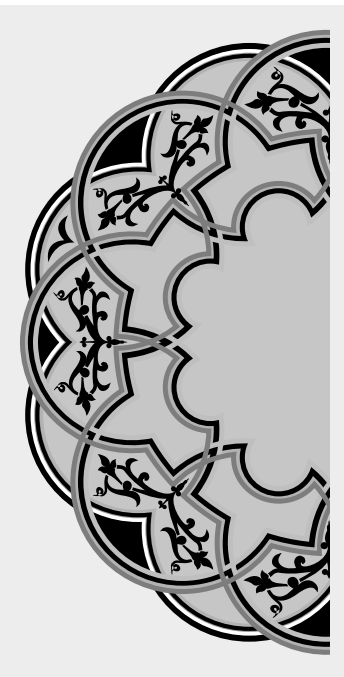

\section{"Being honest may not get you a lot of FRIENDS but it'll always get you the RIGHT ONES."}

Unknown

\section{AUTHORSHIP AND CONTRIBUTION DECLARATION}

\begin{tabular}{|c|l|l|c|}
\hline Sr. \# & \multicolumn{1}{|c|}{ Author-s Full Name } & Contribution to the paper & Author=s Signature \\
\hline 1 & Dr. Sumera Shaikh & $\begin{array}{l}\text { Manuscript writingand } \\
\text { structucal modeling } \\
\text { Data collection, proof } \\
\text { reading and final drafting }\end{array}$ \\
\hline 2 & Dr. Kiran Wassan &
\end{tabular}

